J. Pihlajamäki • U. Salmenniemi · M. Vänttinen •

E. Ruotsalainen - J. Kuusisto $\cdot$ I. Vauhkonen ·

S. Kainulainen - M. C. Y. Ng • N. J. Cox •

G. I. Bell • M. Laakso

\title{
Common polymorphisms of calpain-10 are associated with abdominal obesity in subjects at high risk of type 2 diabetes
}

Received: 23 January 2006 / Accepted: 9 March 2006 / Published online: 12 May 2006

C) Springer-Verlag 2006

\begin{abstract}
Aims/hypothesis: The mechanisms by which the calpain-10 gene (CAPN10) affects the risk of type 2 diabetes are unclear. Therefore, we investigated the effects of four polymorphisms in CAPN10 (single nucleotide polymorphism [SNP]-43, SNP-44, Insertion/Deletion [Indel]-19 and SNP-63) on insulin secretion, insulin action and abdominal fat distribution in offspring of patients with type 2 diabetes. Subjects and methods: Insulin secretion was determined by an IVGTT, insulin action by the hyperinsulinaemic-euglycaemic clamp and abdominal fat distribution by computed tomography in 158 non-diabetic offspring (age 34.9 \pm 6.3 years [mean \pm SD], BMI $26.2 \pm$ $4.9 \mathrm{~kg} / \mathrm{m}^{2}$ ) of type 2 diabetic patients. Results: SNP-43 ( $p=0.009$ over the three genotypes, adjusted for age, sex, BMI and family relationship) and haplotypes carrying the A allele of SNP-43 were associated with intra-abdominal fat area. The A allele of SNP-43 was associated with intraabdominal fat area in men $(p=0.014)$ but not in women. SNP-44, InDel-19 and SNP-63 were not associated with intra-abdominal fat area or insulin action. Furthermore, we demonstrated in a separate sample of middle-aged men $(n=234)$ who had a history of type 2 diabetes in first-
\end{abstract}

J. Pihlajamäki · U. Salmenniemi · M. Vänttinen · E. Ruotsalainen - J. Kuusisto - I. Vauhkonen · M. Laakso University of Kuopio, Department of Medicine, Kuopio, Finland

J. Pihlajamäki $(\bowtie)$

Joslin Diabetes Center and Harvard Medical School, Boston, MA, USA

e-mail: Jussi.Pihlajamaki@joslin.harvard.edu

Tel.: +1-617-2642773

Fax: +1-617-7322593

S. Kainulainen

University of Kuopio, Department of Clinical Radiology,

Kuopio, Finland

M. C. Y. Ng · N. J. Cox •

G. I. Bell

Departments of Medicine and Human Genetics, University of Chicago,

Chicago, IL, USA degree relatives that the A allele of SNP-43 was associated with a large waist circumference, and high insulin levels in an OGTT. Conclusions/interpretation: SNP-43 of CAPN10 may contribute to the risk of diabetes by regulating abdominal obesity in subjects with high risk of type 2 diabetes.

Keywords Calpain-10 - Insulin resistance $\cdot$ Insulin secretion - Type 2 diabetes - Visceral obesity

Abbreviations CAN10: Calpain-10 gene $\cdot$ InDel: Insertion/deletion - LD: Linkage disequilibrium - SNP: Single nucleotide polymorphism - WBGU: Whole-body glucose uptake

\section{Introduction}

Type 2 diabetes is a heterogeneous disease characterised by insulin resistance and impaired insulin secretion. Abdominal obesity is a major risk factor for insulin resistance and type 2 diabetes [1]. Genetic variation in the calpain 10 gene $(C A P N 10)$ is associated with type 2 diabetes [2]. Calpain-10 is a calcium-activated protein expressed in all human tissues [3], but the biochemical and physiological mechanism(s) by which it affects the risk of type 2 diabetes remain unclear. The $\mathrm{G}$ allele of the single nucleotide polymorphism (SNP)-43, has been associated with insulin resistance [4] and type 2 diabetes in both cross-sectional [2] and prospective studies [5]. However, other studies have not found an association of the $\mathrm{G}$ allele with type 2 diabetes or insulin resistance [6-8], and other SNPs and/or haplotypes in the same locus have been proposed to be more important for glucose metabolism [6, 9-11]. The mechanisms by which the $\mathrm{G}$ allele of SNP-43 leads to lower rates of glucose disposal and higher rates of lipid oxidation [4] are unknown, but have been proposed to be related to high levels of NEFA [12]. Alternatively, polymorphisms in this locus could regulate energy expenditure [4], thermogenesis [13] and insulin secretion [14]. 
In this study we investigated whether SNP-43, SNP-44, insertion/deletion (InDel)-19 and SNP-63 polymorphisms of CAPN10 regulate insulin action, insulin secretion, energy expenditure, substrate oxidation and abdominal obesity in 158 middle-aged Finnish non-diabetic offspring of patients with type 2 diabetes.

\section{Subjects and methods}

Subjects

\section{Study I}

All subjects participating in Study I were of Finnish ancestry. Genetically the Finnish population is relatively homogeneous, originating mainly from southern (European) and eastern (Asian) immigration about 2,000 years ago [15]. The study group consisted of 158 non-diabetic offspring of patients with type 2 diabetes from our ongoing study [16]. Patients with type 2 diabetes were randomly selected from patients living in the Kuopio University Hospital region (population of 250,000). One to four offspring from each family were included and altogether 102 families were studied (57 families with one, 35 families with two, nine families with three, and one family with four offspring). On day 1, all subjects underwent an OGTT to evaluate their glucose tolerance according to the World Health Organization criteria [17]. All subjects had normal liver, kidney and thyroid function, no history of excessive alcohol intake and no severe chronic diseases. Informed consent was obtained from all subjects after the purpose and potential risks of the study were explained to them. The protocol was approved by the Ethics Committee of the University of Kuopio and was in accordance with the Helsinki Declaration.

\section{Study II}

An independent study population was collected to confirm the findings of Study I. The primary aim of this study is to investigate the effects of SNPs in genes of interest with respect to the risk of type 2 diabetes and coronary heart disease in a random sample of Finnish men, aged from 50 to 70 years, living in Kuopio town (population of 90,000), eastern Finland. The first 234 men of this ongoing population-based study to fulfil the following criteria: a history of type 2 diabetes in first-degree relatives of the participants, BMI $<30 \mathrm{~kg} / \mathrm{m}^{2}$ to match BMI of Study I, and a non-diabetic OGTT according to the World Health Organization criteria [17], were included in Study II. The protocol includes a 1-day visit to the Clinical Research Unit of the University of Kuopio. Study II was approved by the Ethics Committee of the University of Kuopio and was in accordance with the Helsinki Declaration.
Methods

Clinical measurements Waist circumference was measured in the middle-point between the lower ribs and iliac crest to the nearest $0.5 \mathrm{~cm}$. Blood pressure was measured in the sitting position after a $10-$ min rest. The mean of two measurements was used in statistical analyses.

Metabolic studies (Study I) On day 2, metabolic studies were performed after an overnight fast. First, an IVGTT was performed to determine the first-phase insulin secretion capacity [18] as previously described [16]. Immediately after an IVGTT, the degree of insulin resistance was evaluated by the euglycaemic clamp technique [19]. After the baseline blood drawing, a priming dose of insulin (Actrapid $100 \mathrm{IU} / \mathrm{ml}$; Novo Nordisk, Gentofte, Denmark) was administered during the initial $10 \mathrm{~min}$ to raise plasma insulin concentration quickly to the desired level, where it was maintained by a continuous insulin infusion of $240 \mathrm{pmol} \cdot \mathrm{kg}^{-1} \cdot \mathrm{min}^{-1}$. Blood glucose was clamped at $5.0 \mathrm{mmol} / 1$ for the next $120 \mathrm{~min}$ by the infusion of $20 \%$ glucose at varying rates according to blood glucose measurements performed at 5-min intervals. The mean rates of glucose infusion during the last hour of the clamp were used to calculate the rates of insulin-stimulated whole-body glucose uptake (WBGU). Indirect calorimetry was performed with a computerised flow-through canopy gas analyser system (Deltatrac; Datex, Helsinki, Finland) as previously described [20]. Gas exchange and urinary nitrogen excretion were measured in the fasting state and during the last $30 \mathrm{~min}$ of the euglycaemic clamp. The first 10 min of each measurement was discarded and the mean value of the last $20 \mathrm{~min}$ was used in calculations. The rates of glucose and lipid oxidation and energy expenditure were calculated according to Ferrannini [21]. The rates of non-oxidative glucose disposal during the euglycaemic clamp were estimated by subtracting the rates of glucose oxidation from the rates of WBGU.

Fat distribution (Study I) Abdominal fat distribution was evaluated by computed tomography (Somatom Plus S; Siemens, Erlangen, Germany) at the level of the fourth lumbar vertebra. One hundred and twenty-nine subjects participated in the computed tomography study. Subcutaneous and intra-abdominal fat areas were calculated as previously described [22].

Analytical methods Plasma glucose levels in the fasting state and in the OGTT (Studies I and II) and IVGTT and blood glucose levels during the euglycaemic clamp (Study I) were measured by the glucose oxidase method (2300 Stat Plus; Yellow Springs Instruments, Yellow Springs, OH, USA). For the determination of plasma insulin, blood was collected in EDTA-containing tubes, and after centrifugation the plasma was stored at $-20^{\circ} \mathrm{C}$ until the analysis. Plasma insulin concentration was determined by a commercial double-antibody solid-phase RIA (Phadeseph Insulin RIA 100; Pharmacia Diagnostics AB, Uppsala, 
Sweden). An insulinogenic index was calculated as a ratio between changes in insulin and glucose during the first $30 \mathrm{~min}$ of the OGTT. Lipoprotein fractionation was performed by ultracentrifugation and selective precipitation, as previously described [23]. Cholesterol and triglyceride levels from whole serum and lipoprotein fractions were assayed by automated enzymatic methods (Boehringer-Mannheim, Mannheim, Germany). Serum NEFA were determined from fresh frozen samples by an enzymatic method (Wako Chemicals $\mathrm{GmbH}$, Neuss, Germany). Non-protein urinary nitrogen was measured by an automated Kjeldahl method.

Genotyping of the SNPs in CAPN10 Genotyping of SNP43, SNP-44 and SNP-63 of CAPN10 was carried out using TaqMan Allelic Discrimination Assays (Applied Biosystems, Foster City, CA, USA). Primers are available upon request (J. Pihlajamäki). The TaqMan genotyping reaction was amplified on a GeneAmp PCR system 2700 and fluorescence was detected using an ABI Prism 7000 sequence detector (Applied Biosystems). The insertion/ deletion polymorphism InDel-19 of CAPN10 was amplified using published PCR primers [6], and PCR products were separated on a $3 \%$ NuSieve agarose gel. We used the following coding for the alleles of CAPN10; SNP-43 (rs3792267): $\mathrm{G}=$ allele 1, $\mathrm{A}=$ allele 2; SNP-44 (rs2975760): $\mathrm{T}=$ allele 1, C=allele 2; InDel-19 (rs3842570): two copies of a 32 bp repeat=allele 1 , three copies of a $32 \mathrm{bp}$ repeat=allele 2; and SNP-63 (rs5030952): C=allele 1, $\mathrm{T}=$ allele 2. Only four SNP-43, InDel-19 and SNP-63 haplotypes were found $(111,121,112$ and 221). In this study the C allele of the SNP-44 was observed only with haplotype 111 (Table 1). We re-genotyped 10\% of samples. So far, reproducibility of the results in this and other studies has been $100 \%$.

\section{Statistical analyses}

Analysis of the data was performed with the SPSS/Win programs (version 10.0; SPSS, Chicago, IL, USA). Insulin, NEFA and triglyceride concentrations and insulinogenic index were $\log$ transformed before statistical analyses to achieve a normal distribution. The effect of genotypes in families was studied with a mixed linear model including age, sex, BMI and family relationship as covariates when appropriate (Study I). In Study II, analysis of covariance (ANCOVA) was applied to adjust for confounding variables. For the haplotype analysis of CAPN10, haplotype frequencies were estimated and likely haplotypes reconstructed for each individual using the MERLIN program [24]. The effect of each haplotype on quantitative parameters was analysed with the family-based test of linkage disequilibrium (LD) using the QTDT program with age, sex and BMI as covariates, when appropriate [25]. A value of $p<0.05$ was considered as statistically significant. Data are presented as means \pm SD.

\section{Results}

Subjects in Study I were middle-aged (age $34.9 \pm 6.3$ years $[$ mean $\pm \mathrm{SD}]$ ), their BMI was slightly above normal range $\left(26.2 \pm 4.9 \mathrm{~kg} / \mathrm{m}^{2}\right)$ and they were non-diabetic on the basis of the OGTT (130 had normoglycaemia, three had isolated impaired fasting glucose and 25 had impaired glucose tolerance). The genotypes of SNP-44, SNP-43, InDel-19 and SNP-63 of CAPN10 were in Hardy-Weinberg equilibrium. SNP-43, InDel-19 and SNP-63 were in LD with each other (all pairwise $\mathrm{D}^{\prime}>0.92$ and $p<0.006$ ). In addition, SNP-44 was in LD with SNP-43 and InDel-19 $\left(\mathrm{D}^{\prime}>0.80\right.$, $p<0.05$ ). Five haplotypes could be formed from the four polymorphisms (Table 1). No association of the genotypes with abnormal glucose tolerance was observed $(p=0.712$, impaired fasting glucose and impaired glucose tolerance combined).

In QTDT analysis only the 1221 haplotype was significantly associated with measures of glucose metabolism and intra-abdominal fat area (Table 1). Subjects with this haplotype had higher levels of 2-h insulin in the OGTT ( $p=0.023$, adjusted for age, sex and BMI), higher levels of fasting triglycerides $(p=0.016)$, lower rates of WBGU $(p=0.010)$ and higher amount of intra-abdominal fat ( $p=0.004)$ than subjects without the haplotype. No effect of this haplotype on BMI, total or HDL-cholesterol, serum NEFA, insulin secretion (measured as insulin AUC during

Table 1 The effect of the CAPN10 haplotypes on glucose tolerance and hyperinsulinaemia in an OGTT, fasting serum triglycerides, the rates of WBGU and intra-abdominal fat area (IAF) in 158 offspring of patients with type 2 diabetes (QTDT-adjusted for age, sex and BMI)

\begin{tabular}{|c|c|c|c|c|c|c|c|c|}
\hline $\begin{array}{l}\text { Haplotype } \\
\text { (SNP-44-SNP-43- } \\
\text { InDel-19-SNP-63) }\end{array}$ & Frequency & $\begin{array}{l}\text { Fasting glucose } \\
(\mathrm{mmol} / \mathrm{l})\end{array}$ & $\begin{array}{l}\text { 2-h glucose } \\
(\mathrm{mmol} / \mathrm{l})\end{array}$ & $\begin{array}{l}\text { Fasting insulin } \\
(\mathrm{pmol} / \mathrm{l})\end{array}$ & $\begin{array}{l}\text { 2-h insulin } \\
(\mathrm{pmol} / \mathrm{l})\end{array}$ & $\begin{array}{l}\text { Total triglycerides } \\
(\mathrm{mmol} / \mathrm{l})\end{array}$ & $\begin{array}{l}\text { WBGU/ } \\
\text { LBM }\end{array}$ & $\begin{array}{l}\text { IAF } \\
\left(\mathrm{cm}^{2}\right)\end{array}$ \\
\hline 1121 & 0.33 & $5.2 \pm 0.4$ & $6.3 \pm 1.0$ & $48.6 \pm 22.3$ & $249.2 \pm 169.0$ & $1.17 \pm 0.57$ & $55.7 \pm 18.4$ & $108 \pm 63$ \\
\hline 1221 & 0.23 & $5.2 \pm 0.4$ & $6.5 \pm 1.5$ & $55.5 \pm 30.3$ & $311.5 \pm 225.5^{\mathrm{a}}$ & $1.29 \pm 0.70^{\mathrm{a}}$ & $52.6 \pm 16.2^{\mathrm{a}}$ & $115 \pm 74^{b}$ \\
\hline 2111 & 0.20 & $5.1 \pm 0.4$ & $6.0 \pm 1.5$ & $47.1 \pm 26.1$ & $243.4 \pm 181.3$ & $1.10 \pm 0.42$ & $60.0 \pm 16.5$ & $100 \pm 48$ \\
\hline 1111 & 0.13 & $5.1 \pm 0.4$ & $6.1 \pm 1.0$ & $50.7 \pm 24.8$ & $224.6 \pm 155.0$ & $1.23 \pm 0.59$ & $54.8 \pm 14.8$ & $104 \pm 60$ \\
\hline 1112 & 0.11 & $5.1 \pm 0.4$ & $6.1 \pm 1.2$ & $51.7 \pm 21.0$ & $283.4 \pm 227.0$ & $0.99 \pm 0.55$ & $59.3 \pm 14.3$ & $79 \pm 48$ \\
\hline
\end{tabular}

Values are means \pm SD

${ }^{\mathrm{a}} p<0.05$ and ${ }^{\mathrm{b}} p<0.01$ in QTDT analysis against subjects without the studied haplotype

For coding of the genotypes, see Methods

$W B G U / L B M$ whole-body glucose uptake per lean body mass $\left(\mu \mathrm{mol} \cdot \mathrm{kg}\right.$ lean body $\left.\mathrm{mass}^{-1} \cdot \mathrm{min}^{-1}\right)$ 
the first 10 min of the IVGTT or as an insulinogenic index) or on the rates of energy expenditure and substrate oxidation was observed (data not shown). Combined haplogenotypes of SNP-43, InDel-19 and SNP-63 had no statistically significant effect on insulin sensitivity or intraabdominal fat area (data not shown).

The effect of the 1221 haplotype was due to the effect of SNP-43 only. SNP-43 was associated with larger area of intra-abdominal fat ( $p=0.009$, adjusted for age, sex, BMI and family relationship) and tended to be associated with higher 2-h insulin in the OGTT ( $p=0.059)$, higher fasting triglycerides $(p=0.071)$ and lower rates of WBGU per lean body mass ( $p=0.062$, adjusted for age, sex and family relationship, Table 2). The association of the A allele of SNP-43 with lower rates of WBGU was not significant if adjusted for intra-abdominal fat area $(p=0.449)$. However, the association with high intra-abdominal fat area $(p=0.015)$, and high ratio of intra-abdominal fat to total abdominal fat area $(p=0.005)$ remained significant after the adjustment for the rates of WBGU.

We found a statistically significant interaction between sex and SNP-43 ( $p=0.037$, adjusted for age, BMI and the rates of WBGU) on their effects on intra-abdominal fat area. The A allele of SNP-43 was associated with a large intra-abdominal fat area in men $(p=0.014)$, but not in women $(p=0.396)$ (Fig. 1). No interaction of SNP-43 with sex or their effects on the rates of WBGU or other parameters was observed. SNP-44 tended to be associated with the rates of WBGU $(p=0.053)$ but this was probably because of LD with SNP-43. InDel-19 and SNP-63 were not associated with any of the parameters measured. We also found a statistically significant interaction between BMI (formed by dividing study population using median

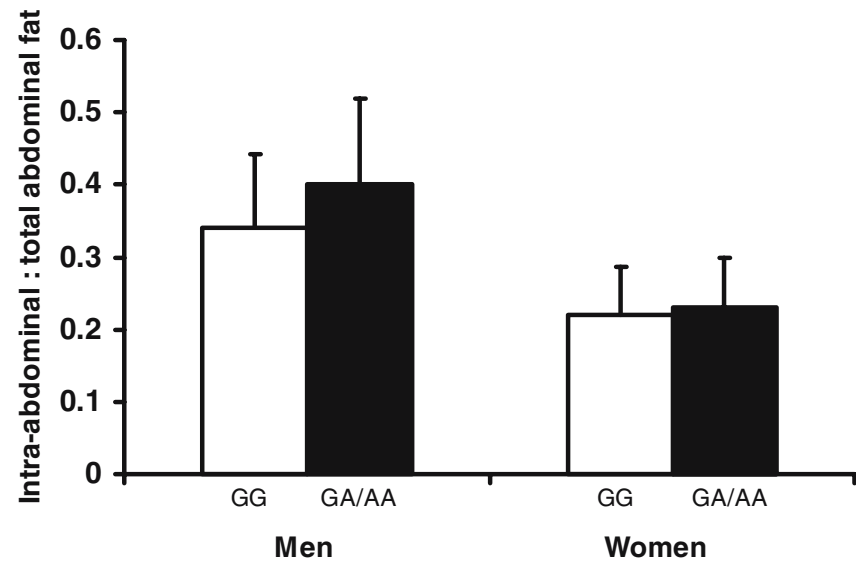

Fig. 1 The effect of SNP-43 on the ratio of intra-abdominal to total abdominal fat area measured with computed tomography by sex (adjusted for age, BMI and the rates of WBGU). Data are means \pm SD. $p=0.014$

BMI of $25.3 \mathrm{~kg} / \mathrm{m}^{2}$ as a cut-off point) and SNP-43 on their effects on intra-abdominal fat area $(p=0.034)$. Figure 2 demonstrates that BMI correlated more strongly with the amount of intra-abdominal fat in subjects with the A allele than in subjects with the GG genotype.

Study II gave further evidence of the association of SNP43 with abdominal obesity in men (Table 3). Waist circumference tended to be larger in carriers of the A allele than in carriers of the GG genotype in Study I, and it was larger in carriers of the A allele than in carriers of the GG genotype in Study II $(p=0.022)$. In both studies, diastolic blood pressure and insulin AUC in an OGTT were higher among the carriers of the A allele of SNP-43 than among carriers of the GG genotype.

Table 2 Characteristics of the study group according to the genotypes of SNP-43

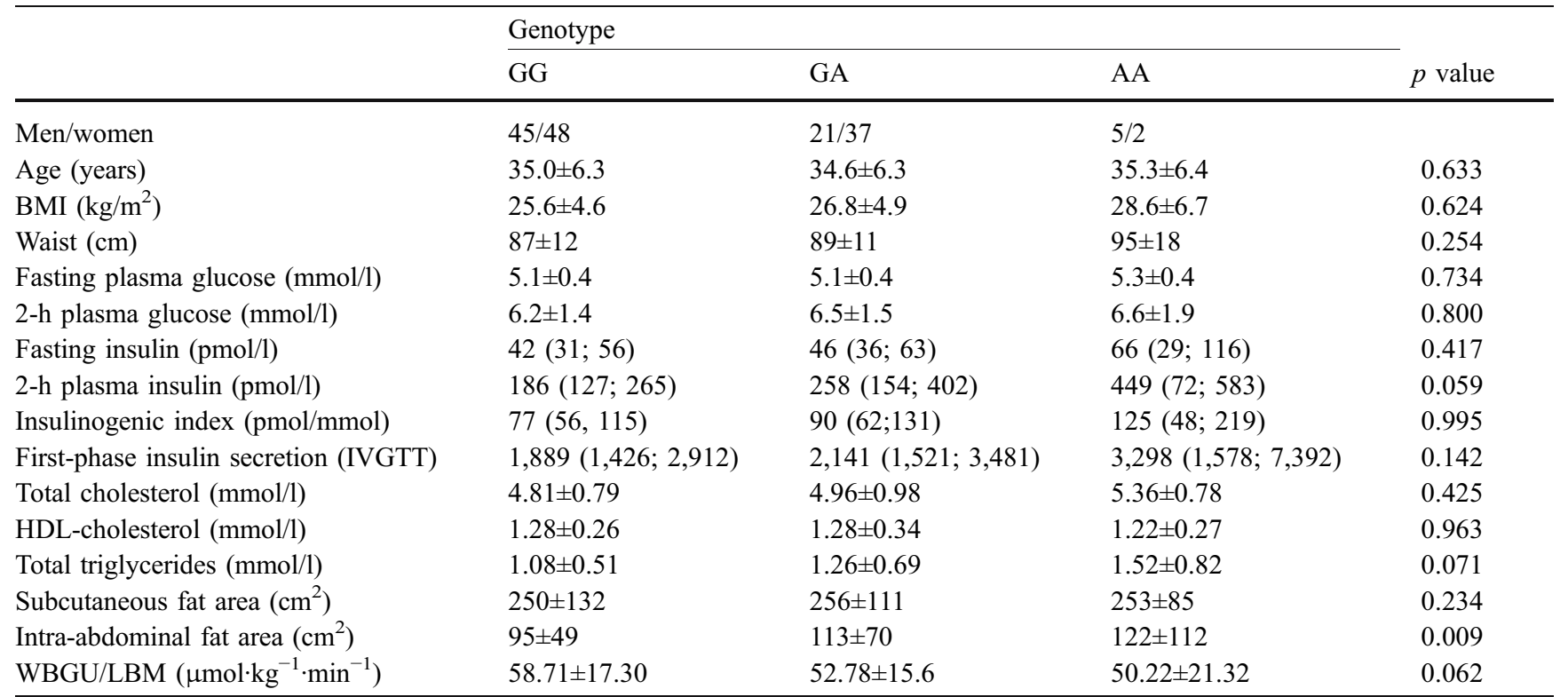

Values are means $\pm \mathrm{SD}$; median and 25 th and 75 th percentiles (in parentheses) are shown for plasma insulin, insulinogenic index and firstphase insulin secretion.

Mixed linear model using age, sex, BMI and family relationship as covariates (for WBGU, sex, sex and family relationship)

$W B G U / L B M$ whole-body glucose uptake per lean body mass 


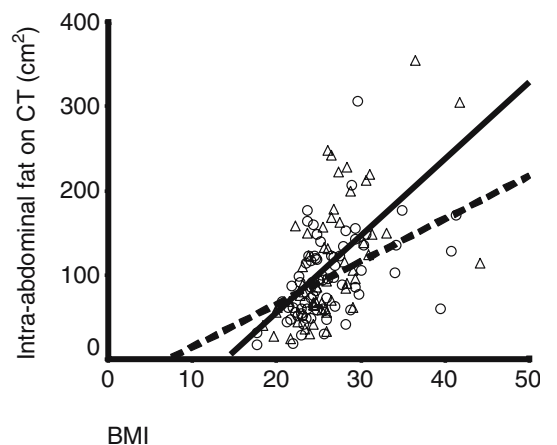

Fig. 2 The correlation between BMI and intra-abdominal fat in subjects with the GA/AA genotype (triangles, solid lines) or the GG genotype (circles, dashed lines) of SNP-43. CT computed tomography. $r^{2}=035, \quad p<0.001 \quad$ (GG/AA genotype); $r^{2}=021$, $p<0.001$ (GG genotype)

\section{Discussion}

Genetic variation in CAPN10 increases the risk of type 2 diabetes $[2,26,27]$ with variants affecting risk alone (e.g. SNP-44 and SNP-43) or in combination (e.g. SNP-43, InDel-19 and SNP-63 haplotype). The variants in CAPN10 can result in the synthesis of a mutant protein (e.g. Thr504Ala) or may affect the levels of expression of calpain-10, e.g. SNP-43 in fat and skeletal muscle $[2,4,28$,
29]. The novel finding of the present study was that SNP43 affects intra-abdominal obesity and insulin sensitivity in offspring of patients with type 2 diabetes (Study I). Furthermore, in an independent sample of men who had a history of type 2 diabetes in first-degree relatives, the A allele of SNP-43 was associated with surrogate markers of abdominal obesity (waist) and insulin sensitivity (insulin AUC in an OGTT).

Insulin resistance is an inherited trait in offspring of patients with type 2 diabetes [30], and precedes this disease. The central question is how CAPN10 regulates insulin action in patients at risk of developing diabetes. In our study the A allele of SNP-43 was associated with intraabdominal fat area even after the adjustment for insulin sensitivity. The GG genotype has been associated with improved insulin action in isolated subcutaneous adipocytes [31], which could explain the preferential storage of fat in subcutaneous depots, in contrast to intra-abdominal fat that is less sensitive to insulin action [32]. Lower accumulation of intra-abdominal fat could then explain better whole-body insulin sensitivity in subjects with the GG genotype in this study. The same genotype GG has also been associated with lower $C A P N 10$ expression in fat, and thus could have a role in adipocyte metabolism [28]. Interestingly, interaction between SNP-43 and obesity resembles the findings of another identified type 2 diabetes

Table 3 Clinical characteristics of men in Studies I and II according to the genotypes of SNP-43

\begin{tabular}{|c|c|c|c|c|c|c|}
\hline & \multicolumn{3}{|l|}{ Study I } & \multicolumn{3}{|l|}{ Study II } \\
\hline & GG & GA/AA & $p$ value & GG & GA/AA & $p$ value \\
\hline No. & 45 & 26 & & 140 & 94 & \\
\hline Age (years) & $35.4 \pm 6.5$ & $33.9 \pm 5.5$ & 0.365 & $57.6 \pm 5.9$ & $56.8 \pm 5.7$ & 0.300 \\
\hline BMI $\left(\mathrm{kg} / \mathrm{m}^{2}\right)$ & $25.0 \pm 2.7$ & $27.4 \pm 4.3$ & 0.075 & $26.0 \pm 2.3$ & $26.1 \pm 2.1$ & 0.725 \\
\hline Waist $(\mathrm{cm})$ & $90 \pm 9$ & $96 \pm 10$ & 0.204 & $94 \pm 7$ & $96 \pm 7$ & 0.022 \\
\hline $\begin{array}{l}\text { Diastolic blood pressure } \\
(\mathrm{mmHg})\end{array}$ & $85 \pm 11$ & $90 \pm 8$ & 0.014 & $87 \pm 8$ & $90 \pm 11$ & 0.011 \\
\hline Glucose AUC (OGTT) & $716 \pm 115$ & $721 \pm 143$ & 0.114 & $870 \pm 128$ & $881 \pm 139$ & 0.564 \\
\hline Insulin AUC (OGTT) & $\begin{array}{l}22,925 \\
(19,134 ; 29,875)\end{array}$ & $\begin{array}{l}32,841 \\
(21,483 ; 56,920)\end{array}$ & 0.011 & $\begin{array}{l}26,712 \\
(17,865 ; 39,843)\end{array}$ & $\begin{array}{l}28,616 \\
(19,460 ; 46,235)\end{array}$ & 0.039 \\
\hline HDL-cholesterol (mmol/1) & $1.18 \pm 0.21$ & $1.10 \pm 0.21$ & 0.871 & $1.50 \pm 0.38$ & $1.53 \pm 0.39$ & 0.662 \\
\hline Total triglycerides $(\mathrm{mmol} / \mathrm{l})$ & $1.22 \pm 0.57$ & $1.47 \pm 0.81$ & 0.445 & $1.41 \pm 0.82$ & $1.36 \pm 0.87$ & 0.672 \\
\hline Subcutaneous fat area $\left(\mathrm{cm}^{2}\right)$ & $198 \pm 72$ & $223 \pm 77$ & 0.445 & ND & ND & - \\
\hline $\begin{array}{l}\text { Intra-abdominal fat area } \\
\left(\mathrm{cm}^{2}\right)\end{array}$ & $106 \pm 49$ & $157 \pm 82$ & 0.014 & ND & ND & - \\
\hline $\begin{array}{l}\text { WBGU/LBM } \\
\left(\mu \mathrm{mol} \cdot \mathrm{kg}^{-1} \cdot \mathrm{min}^{-1}\right)\end{array}$ & $56.72 \pm 18.02$ & $50.21 \pm 16.79$ & 0.763 & ND & ND & - \\
\hline
\end{tabular}

Values are means \pm SD; median and 25 th and 75 th percentiles (in parentheses) are shown for insulin AUC (OGTT) and first-phase insulin secretion.

Study I: Mixed linear model including age, BMI and family relationship as covariates (for WBGU age and family relationship). Study II: ANCOVA including age and BMI as covariates

$W B G U / L B M$ whole-body glucose uptake per lean body mass, $N D$ not determined 
risk polymorphism, Pro12Ala of the peroxisome proliferator-activated receptor $\gamma 2$ gene, which is known to regulate adipocyte metabolism. The effect of this polymorphism is also different in lean and obese subjects, because the insulin sensitive Ala12 allele [33] is associated with lower prevalence of type 2 diabetes [34] but increased weight gain [35] and diabetes risk in obese subjects [36].

The effect of the A allele of SNP-43 on intra-abdominal obesity (Study I) was observed in men but not in women (Fig. 1, Table 3). This finding is supported by another sample of men (Study II) when waist circumference was used as a surrogate marker of abdominal obesity. This sexrelated difference could be due to the higher prevalence of central obesity in men. No association of SNP-43 and waist-to-hip ratio was observed in our study, in agreement with a study of 70-year-old Swedish men [37]. An interaction of SNP-43 with sex (Fig. 1) or BMI (Fig. 2) on their effects on abdominal obesity has not been reported in previous studies, which could explain discrepant findings. However, we cannot exclude the possibility that our findings are population specific.

The GG genotype of SNP-43 has been associated with type 2 diabetes and insulin resistance [4, 27], whereas in this study the A allele, and a haplotype carrying this allele, was associated with intra-abdominal obesity. These apparently discrepant findings may be due to the fact that the effects of calpain-10 on clinical measures may be complex and difficult to investigate in cross-sectional studies, similar to the Pro12Ala polymorphism of the peroxisome proliferator-activated receptor $\gamma 2$ gene [33-36]. Subjects with the GG genotype of SNP-43 may originally have better adipocyte and whole-body insulin sensitivity and this may promote the accumulation of fat, e.g. in skeletal muscle and liver.

In conclusion, our study suggests that SNP-43 is associated with abdominal obesity in subjects at high risk of developing type 2 diabetes, indicating that calpain-10 may have a role in adipocyte metabolism.

Acknowledgements This study was supported by grants from the Academy of Finland, the Finnish Diabetes Research Foundation, the EVO-fund of the Kuopio University Hospital (grant no. 5167) and the European Union (to M. Laakso) (EUGENE2 LSHM-CT2004-512013) and by US Public Health Service Grants DK-20595, DK-47486 and DK-55889. We thank laboratory technicians L. Uschanoff, K. Eirola and A.-L. Gidlund for genotyping.

\section{References}

1. Despres JP (2001) Health consequences of visceral obesity. Ann Med 33:534-541

2. Horikawa Y, Oda N, Cox NJ et al (2000) Genetic variation in the gene encoding calpain-10 is associated with type 2 diabetes mellitus. Nat Genet 26:163-175

3. Ma H, Fukiage C, Kim YH et al (2001) Characterization and expression of calpain 10. A novel ubiquitous calpain with nuclear localization. J Biol Chem 276:28525-28531

4. Baier LJ, Permana PA, Yang X et al (2000) A calpain-10 gene polymorphism is associated with reduced muscle mRNA levels and insulin resistance. J Clin Invest 106:R69-R73
5. Garant MJ, Kao WH, Brancati F et al (2002) SNP43 of CAPN10 and the risk of type 2 Diabetes in African-Americans: the Atherosclerosis Risk in Communities Study. Diabetes 51:231-237

6. Evans JC, Frayling TM, Cassell PG et al (2001) Studies of association between the gene for calpain-10 and type 2 diabetes mellitus in the United Kingdom. Am J Hum Genet 69:544-552

7. Stumvoll M, Fritsche A, Madaus A et al (2001) Functional significance of the UCSNP-43 polymorphism in the CAPN10 gene for proinsulin processing and insulin secretion in nondiabetic Germans. Diabetes 50:2161-2163

8. Hegele RA, Harris SB, Zinman B, Hanley AJ, Cao H (2001) Absence of association of type 2 diabetes with CAPN10 and PC-1 polymorphisms in Oji-Cree. Diabetes Care 24:1498-1499

9. Elbein SC, Chu W, Ren Q et al (2002) Role of calpain-10 gene variants in familial type 2 diabetes in Caucasians. J Clin Endocrinol Metab 87:650-654

10. Fullerton SM, Bartoszewicz A, Ybazeta G et al (2002) Geographic and haplotype structure of candidate type 2 diabetes susceptibility variants at the calpain-10 locus. Am J Hum Genet 70:1096-1106

11. Cassell PG, Jackson AE, North BV et al (2002) Haplotype combinations of calpain 10 gene polymorphisms associate with increased risk of impaired glucose tolerance and type 2 diabetes in South Indians. Diabetes 51:1622-1628

12. Orho-Melander M, Klannemark M, Svensson MK, Ridderstrale M, Lindgren CM, Groop L (2002) Variants in the calpain-10 gene predispose to insulin resistance and elevated free fatty acid levels. Diabetes 51:2658-2664

13. Hoffstedt J, Naslund E, Arner P (2002) Calpain-10 gene polymorphism is associated with reduced beta(3)-adrenoceptor function in human fat cells. J Clin Endocrinol Metab $87: 3362-3367$

14. Lynn S, Evans JC, White C et al (2002) Variation in the calpain-10 gene affects blood glucose levels in the British population. Diabetes 51:247-250

15. Kittles R, Perola M, Peltonen L et al (1998) Dual origins of Finns revealed by $\mathrm{Y}$ chromosome haplotype variation. Am J Hum Genet 62:1171-1179

16. Salmenniemi U, Ruotsalainen E, Pihlajamäki J et al (2004) Multiple abnormalities in glucose and energy metabolism and coordinated changes in levels of adiponectin, cytokines, and adhesion molecules in subjects with metabolic syndrome. Circulation 110:3842-3848

17. Alberti KG, Zimmet PZ (1998) Definition, diagnosis and classification of diabetes mellitus and its complications. Part 1: diagnosis and classification of diabetes mellitus provisional report of a WHO consultation. Diabet Med 15:539-553

18. Galvin P, Ward G, Walters J et al (1992) A simple method for quantitation of insulin sensitivity and insulin release from an intravenous glucose tolerance test. Diabet Med 9:921-928

19. DeFronzo R, Tobin J, Andres R (1979) Glucose clamp technique: a method for quantifying insulin secretion and insulin resistance. Am J Physiol 237:E214-E223

20. Laakso M, Uusitupa M, Takala J, Majander H, Reijonen T, Penttilä I (1988) Effects of hypocaloric diet and insulin therapy on metabolic control and mechanisms of hyperglycemia in obese non-insulin-dependent diabetic subjects. Metabolism 37:1092-1100

21. Ferrannini E (1988) The theoretical bases of indirect calorimetry: a review. Metabolism 37:287-301

22. Sjöstrom L, Kvist H, Cederblad A, Tylen U (1986) Determination of total adipose tissue and body fat in women by computed tomography, $40 \mathrm{~K}$, and tritium. Am J Physiol 250:E736-E745

23. Laakso M, Sarlund H, Mykkänen L (1990) Insulin resistance is associated with lipid and lipoprotein abnormalities in subjects with varying degrees of glucose tolerance. Arteriosclerosis 10:223-231

24. Abecasis GR, Cherny SS, Cookson WO, Cardon LR (2002) MERLIN - rapid analysis of dense genetic maps using sparse gene flow trees. Nat Genet 30:97-101 
25. Abecasis GR, Cardon LR, Cookson WO (2000) A general test of association for quantitative traits in nuclear families. Am J Hum Genet 66:279-292

26. Weedon MN, Schwarz PE, Horikawa Y et al (2003) Meta-analysis and a large association study confirm a role for calpain-10 variation in type 2 diabetes susceptibility. Am J Hum Genet 73:1208-1212

27. Song Y, Niu T, Manson JE, Kwiatkowski DJ, Liu S (2004) Are variants in the CAPN10 gene related to risk of type 2 diabetes? A quantitative assessment of population and family-based association studies. Am J Hum Genet 74:208-222

28. Carlsson E, Fredriksson J, Groop L, Ridderstrale M (2004) Variation in the calpain-10 gene is associated with elevated triglyceride levels and reduced adipose tissue messenger ribonucleic acid expression in obese Swedish subjects. J Clin Endocrinol Metab 89:3601-3605

29. Carlsson E, Poulsen P, Storgaard H et al (2005) Genetic and nongenetic regulation of CAPN10 mRNA expression in skeletal muscle. Diabetes 54:3015-3020

30. Vauhkonen I, Niskanen L, Vanninen E, Kainulainen S, Uusitupa M, Laakso M (1998) Defects in insulin secretion and insulin action in non-insulin-dependent diabetes mellitus are inherited. Metabolic studies on offspring of diabetic probands. J Clin Invest 101:86-96

31. Hoffstedt J, Ryden M, Lofgren P, Orho-Melander M, Groop L, Arner P (2002) Polymorphism in the Calpain 10 gene influences glucose metabolism in human fat cells. Diabetologia 45:276-282
32. Zierath JR, Livingston JN, Thorne A et al (1998) Regional difference in insulin inhibition of non-esterified fatty acid release from human adipocytes: relation to insulin receptor phosphorylation and intracellular signalling through the insulin receptor substrate-1 pathway. Diabetologia 41:1343-1354

33. Deeb S, Fajas L, Nemoto M et al (1998) A Pro12Ala substitution in the human peroxisome proliferator activated receptor gamma 2 is associated with decreased receptor activity, lower body mass index and improved insulin sensitivity. Nature Genetics 20:284-287

34. Altshuler D, Hirschhorn JN, Klannemark M et al (2000) The common PPARgamma Pro12Ala polymorphism is associated with decreased risk of type 2 diabetes. Nat Genet 26:76-80

35. Lindi V, Sivenius K, Niskanen L, Laakso M, Uusitupa MI (2001) Effect of the Pro12Ala polymorphism of the PPARgamma2 gene on long-term weight change in Finnish nondiabetic subjects. Diabetologia 44:925-926

36. Lindi VI, Uusitupa MI, Lindstrom J et al (2002) Association of the Pro12Ala polymorphism in the PPAR-gamma2 gene with 3year incidence of type 2 diabetes and body weight change in the Finnish Diabetes Prevention Study. Diabetes 51:2581-2586

37. Rasmussen SK, Urhammer SA, Berglund L et al (2002) Variants within the calpain-10 gene on chromosome $2 \mathrm{q} 37$ (NIDDM1) and relationships to type 2 diabetes, insulin resistance, and impaired acute insulin secretion among Scandinavian Caucasians. Diabetes 51:3561-3567 